part and shows that montana Grt. (nec Morr.) should be known as colorado Smith which I propose to consider as the genotype of Agrotiphila Grt. Agrotimorpha Benj. will therefore fall as a synonym of Agrotiphila Grt. and Orosagrotis Hamp. must be resurrected for the species montana Morr. and incognita Sm. It seems most probable that the subgenus Menada Kozh. (1937, Fauna U.S.S.R., Vol. XIII (3), Argotinae, pp. 526, 593, 644, 651) with genotype nomas Ersch., will fall to Orosagrotis; the female genitalia of incognita Sm. are almost an exact match for Kozhantschikov's figure 305 of the genitalia of nomas.

While on this subject it might be noted that the more recently described churchillensis McD. (1932, Can. Ent. LXIV, 105) should be removed from Agrotiphila and placed in Euxoa near colata Grt. and its allies; since describing the species I have been able to examine the genitalia of a female of this species and find that the type of bursa and ductus seminalis is distinctly that of the colata group and not of the species now placed in Orosagrotis.

\title{
IVOR JESMOND WARD, 1908-1947
}

It is with deep regret that we record the death, at the age of 38 years, of Ivor Jesmond Ward, Provincial Entomologist for British Columbia, which occurred on February 5, 1947. Born in England, he came to Vernon, British Columbia, with his parents, 35 years ago. In 1926 he joined the staff of the Dominion Entomological Laboratory in Vernon, and after obtaining his Bachelor of Science degree in 1938 from the University of Alberta, he was employed continuously on field crop insect investigations in Vernon and Kamloops until, in 1943, he accepted the position of Provincial Entomologist.

With Ivor Ward's passing the Entomological Society of British Columbia loses a member and a friend, and the Provincial and Dominion Departments of Agriculture a valued worker. As Provincial Entomologist he might have had a long and valuable career, for few men have the ability for making friends better developed than did Ivor Ward, and he had a personality particularly suited to the field of extension entomology.

He will always be remembered by the stockmen of the British Columbian cattle ranges for the part he played in the study of their grasshopper problems, and in the organization of the grasshopper control zones.

After his appointment as Provincial Entomologist he had charge of the control work for the Colorado potato beetle, and was interested in devising better control methods for the various fruit, vegetable, and seed insecis throughout the province, and in preparing provincial publications on insect control.

He is survived by his wife, formerly Marjorie Glover of Kamloops; his father, Fred Ward, of Vernon; and two sisters, Mrs. K. Burnham of Vernon and Mrs. Sid Walker of Vancouver.

E. R. Buckell. 